\title{
Chinese Adolescents' Conceptions of Teacher Authority and Their Relations to Rule Violations in School
}

\author{
Jianjin Liu \\ (Guangdong University of Foreign Studies, Guangzhou, liujianjinljj@126.com)
}

\section{Introduction}

Teacher authority refers to teachers' power or influence on students which makes them to believe or obey in the process of education and teaching (Zhang \& Li 2003). It is manifested as teachers' control and management of students and students' dependence and obedience to teachers (Tian 1998). It not only plays a direct role in education management, but also has a potential impact on the effect of other teachers' educational practices (Yu 2005). Thus, teacher authority is a description of the relationship between teachers and students. Clifton, R. A. and Roberts. L. W. put forward four types of teacher authority: legal authority, traditional authority, charismatic authority and professional authority. The former two originated from the social and educational system, the latter from the teacher's personal factors, and the teacher's general authority was the resultant force of the interaction of the four levels of authority.

After entering the modern society, the lofty status of teachers has been suffering unprecedented challenges. Some scholars have asserted that, part of teacher authority, namely the authority comes from knowledge and institution, is suffering a disastrous decline (Luo 2010). Teacher authority in the Internet age is faced with the danger of being thoroughly dispelled. Some people even claim that teacher authority has become out of date and should be abandoned. But more people believe teacher authority is very necessary for ensuring students' rights, realizing students' freedom and promoting their development in all aspects. Just as Deng \& Wang (2007) put it, "in education, teacher authority is indispensable. Therefore, the essence of the problem is not the nessecity of teacher authority, but what kind of teacher authority we need." Therefore, how to reconstruct or transform teacher authority has become a hot topic in education. Zhang Liangcai and Li Runzhou (2003) thought that in modern education it is becoming more 
and more urgent to transform teacher authority from external dependent authority (traditional, legal authority) into internal generating authority (charismatic, professional authority). Cao Jing and Ming Qinghua (2012) believed that the transformation of teacher authority needed the protection from external system and the improvement of teachers' inner quality, which was reflected in the communication between teachers and students in educational practice.

However, as mentioned above, teacher authority is a concept of relationship, involving the authority of the subject (teachers) and authority of the receptor (students). Therefore, how to reshape teacher authority is not a one-way issue, i.e. it's not just concerning how to make teachers become more authoritative, but also related to how students understand and perceive the authority of teachers, that is, students' cognition of teacher authority matters a lot in the process.

Social Cognitive Domain Theory (hereinafter referred to as Domain Theory) has conducted detailed and in-depth studies of the cognition of teacher authority. Domain Theory is one of the latest development of moral psychology in the west. The tenet of the theory is: the diversity of social interactions results in the heterogeneity of social rules or events, then forms the heterogeneity in social cognitive domains. At present, moral domain, conventional domain and personal domain have been widely recognized and studied. Moral domain focuses on the direct impact of intrinsic consequence on others, and its core concepts are human welfare, fairness and rights. Generally speaking, the consequences of moral violations are the most serious and deserve more severe punishment. Social conventions are the rules of behavior consistency that coordinate social interaction. They are subject to specific social situations and are arbitrary behaviors relative to social situations. Conventional rules mainly involve the normal operation of social organizations and the maintenance of social order. Violations of conventions do not cause losses to the rights and interests of others, so they are not as serious as moral violations (Turiel 1993). Personal domain focuses mainly on actors themselves. The consequences of personal behavior only affect the actor him/herself, and will not have adverse effects on others and social organizations (Nucci 1981). Prudential domain belongs to personal domain, which mainly refers to the potential or actual harm to the actor himself (Tisak \& Turiel 1984). There are interactions and interplay between those domains.

Domain Theory researchers found that children and adolescents perceived teacher authority in different ways in different social domains. Smetana and Bitz (1996) found that students recognized teacher authority in moral domain most, followed by conventional and prudential domain; but to a great degree they didn't recognize and accept teacher authority in contextually conventional and personal domain. Yariv (2009) also found that students may sometimes deny teacher authority, and further discussed the boundaries of teacher authority from the perspective of students' understanding and acceptance, and drew the conclusion that there were differences in the acceptance and recognition of teacher authority in different social domains. Pace and Hemmings (2007) emphasized 
that legitimate teacher authority was value laden and culturally sensitive. In different sociocultural and instructional contexts, different forms of teacher authority might be perceived differently and have differential effects. Researchers have shown that students in different cultures value different authority attributes (Kim 1998; Laupa \& Tse 2005).

Do Chinese adolescents perceive teacher authority differently in moral, conventional, contextually conventional, personal and prudential domain? Is there any correlation between authority cognition in various domains and disciplinary actions in these domains? These are the question that this study tries to answer.

\section{Method}

\subsection{Subjects}

The sample consisted 297 adolescents from grade 7, 9 and 11, with 131 males and 166 females, 142 from big cities and 155 from countryside in China. The mean ages were 13.06 years ( $\mathrm{SD}=.62$ ), 15.00 years ( $\mathrm{SD}=.59$ ), and 17.18 years $(\mathrm{SD}=.59$ ), respectively. $47.8 \%$ of the sample came from big cities in China, with more advanced economy and culture; $52.2 \%$ of them came from countryside in mainland China, with more traditional culture and lifestyles. The majority of the sample lived in intact, two-parent families (69\%); 8.6\% lived in single-parent families; $8.9 \%$ lived with grand-parents; $3 \%$ of them lived in stepparent families; the others lived alone or with other relatives.

\subsection{Stimuli}

To generate stimuli that were relevant across schools and grades, the author interviewed students and teachers from the seven participating schools about typical rule violations in their schools. The stimuli for this study were drawn from those interviews and were chosen to be relevant to all three grades included in this study. The stimuli were 19 hypothetical transgressions, 4 moral, conventional, personal, contextually conventional items, and three prudential ones. The items were presented in Table 1. Each of the contextually conventional events can be seen as an act that is typically treated as personal in other contexts but was regulated in the school in this study (Smetana 1996). The definitions of morality, conventionality, personal choice and prudence and the assignment of stimuli to conceptual domains were based on previous research (Nucci 1981; Turiel 1983; Smetana 1981; 1988; 1996; Tisak 1993).

\subsection{Student questionnaires}

\subsubsection{Background information.}

At the beginning of the questionnaire, students were required to offer their age, gender, grade, parents' marital status, living area (countryside or big city). Students also indicated their average academic performance with choice of "excellent", "average", and 
"poor". Finally, students were asked "how much you like school" on a five-point scale ranging from "dislike very much" (1) to "like very much" (5).

\begin{tabular}{|l|l|}
\hline \multicolumn{1}{|c|}{ Domain } & \multicolumn{1}{|c|}{ Stimulus Items } \\
\hline Moral & $\begin{array}{l}\text { Cheating in an exam } \\
\text { Stealing money from another student } \\
\text { Laughing at other students } \\
\text { Fighting with other students }\end{array}$ \\
\hline Conventional & $\begin{array}{l}\text { Being late for school } \\
\text { Chitchatting in a class } \\
\text { Jumping the queue at lunch } \\
\text { Going to school with sleepers }\end{array}$ \\
\hline Personal & $\begin{array}{l}\text { Keeping short hair } \\
\text { Wearing earrings and necklace } \\
\text { Sitting next to friends at lunch } \\
\text { How to spend pocket money }\end{array}$ \\
\hline conventional & $\begin{array}{l}\text { Peaving classroom without permission to go to } \\
\text { lavatory } \\
\text { Using cell phones at classroom }\end{array}$ \\
\hline $\begin{array}{l}\text { Smoking cigarettes at school } \\
\text { Surinking alcohol at school }\end{array}$ \\
\hline
\end{tabular}

Table 1: Stimulus Items for the School Authority Questionnaire 


\subsubsection{Act and rule evaluations.}

Then participants were presented a list of events and asked whether to indicate "whether it is OK or not OK for teachers to make a rule" about each event, assessing the legitimacy of teacher authority. The score of "1" indicates legitimacy assigning to teachers; the score of "0" means nonlegitimacy. Next, participants were asked to evaluate how good or bad it would be to make rules for each issue on a 5 -point scale ranging from 1 (very bad) to 5 (very good), assessing their ratings of rules. Participants then were asked to judge whether or not the acts were "up to the individual to decide", assessing judgments of personal jurisdiction. Responses indicating personal jurisdiction were assigned a score of " 1 ", and responses rejecting personal jurisdiction were assigned "0". Then participants were ask to rate the acts on a 3-point scale ranging from 1 (not bad) to 3 (very bad), assessing their ratings of act severity.

\subsubsection{Alternative authority sources.}

Subjects were asked to check off the person or institutions (the self, teachers, parents, school principals, and the law) that should be able to make rules about each issue or have the authority to govern the behavior. Participants were instructed to choose as many people or authorities as apply. The score of " 1 " means the use of the category; "0" means the category was not used.

\subsubsection{Ratings of the school context.}

The next two questions concerned adolescents' perceptions of their school context. For each issue, they rated the extent to which issues were governed by rules in their schools or classes on a scale ranging from 1 (no rules or expectations) to 3 (strict rules or expectations), assessing the existence of rules. Then they rated the extent that teachers let them decide each issue on a scale ranging from 1 (no input) to 5 (a great deal of input), assessing opportunities for input into decision making.

\subsubsection{Student ratings of misconduct.}

Finally, the participants were asked to indicate their engagement in each of the behavior, over the current school year, on a scale ranging from 1 (never) to 5 (very frequently), assessing school misconduct.

\subsection{Teacher ratings of misconduct}


Class teachers were asked to rate participants' behaviors over the current school year on a 19-item questionnaire that paralleled students' ratings of their behaviors, on a scale ranging from 1 (never) to 5 (very frequently).

\subsection{Procedure}

Researchers visited junior middle schools and senior middle schools, both in countryside and big cities, to invite students to participate in the study. Students were offer a gift for participating in the research. The sample was randomly selected from students, with the permission of their parents. Then students from the same school were asked to finish the questionnaire at the same period of time (about 30 minutes). The researcher read the questionnaire instructions to the participants.

Class teachers were chosen to rate students' behavior, because they were more familiar with students' performance at school. Teachers involved in the research were offer a U-disk as rewards. A total of 14 teachers participated in the teacher ratings.

\subsection{Analyses}

Domain scores were obtained by averaging responses for the items in each domain for each judgment. Then mean responses for each judgment were analyzed using separate 3 (grade) $\times 2$ (gender) $\times 2$ (area) $\times 5$ (domain) repeated-measures analyses of variance (ANOVAs) with grade, gender and area as between subject variables and domain as the repeated measure. Multiple regressions on misconduct were performed to examine the relative contributions of different variables on misconduct.

\section{Results}

\subsection{Evaluations of acts and rules}

Separate ANOVAs were performed on judgments of legitimacy and personal jurisdiction and ratings of act severity and rules. These analyses showed main effects for domains for all four judgments, Fs $(4,1136)=310,96,357.38,407.31,357.36$, $p s<.0001$, respectively. As can be seen in Table 2, moral issues were judged to be more legitimately subject to teacher's authority $(M=.95)$ than all other issues, and prudential and conventional issues were judged to be more legitimately subject to teachers' authority than were contextually conventional and personal issues. Conversely, personal issues were regarded as under personal jurisdiction $(M=.76)$ more than any other issues, and contextually conventional issues $(M=.54)$ were seen as under personal jurisdiction more than were prudential, conventional, or moral issues. 


\begin{tabular}{|c|c|c|c|c|}
\hline \multicolumn{5}{|c|}{$\overline{\text { GRADE }}$} \\
\hline & 7 & 9 & 11 & M \\
\hline \multicolumn{5}{|l|}{ Legitimacy } \\
\hline Moral items & 92.8 & 97.0 & 95.9 & 95.2 \\
\hline Conventional & 89.2 & 83.0 & 80.1 & 84.4 \\
\hline Personal & 53.4 & 35.3 & 27.9 & 39.6 \\
\hline Contextual & 78.4 & 67.0 & 63.0 & 69.9 \\
\hline Prudential & 91.6 & 85.6 & 82.3 & 86.9 \\
\hline \multicolumn{5}{|c|}{ Personal jurisdiction } \\
\hline Moral items & 29.3 & 44.7 & 56.3 & 42.2 \\
\hline Conventional & 35.1 & 50.2 & 65.8 & 49.1 \\
\hline Personal & 61.1 & 81.9 & 87.3 & 76.2 \\
\hline Contextual & 38.9 & 53.5 & 72.8 & 53.6 \\
\hline Prudential & 31.1 & 51.4 & 65.0 & 48.0 \\
\hline \multicolumn{5}{|c|}{ Rule evaluation $^{\mathrm{a}}$} \\
\hline Moral items & 4.37 & 4.30 & 4.09 & 4.27 \\
\hline Conventional & 4.15 & 3.83 & 3.70 & 3.91 \\
\hline Personal & 3.34 & 2.71 & 2.54 & 2.71 \\
\hline Contextual & 3.83 & 3.46 & 3.27 & 3.54 \\
\hline Prudential & 4.00 & 4.10 & 3.85 & 4.14 \\
\hline \multicolumn{5}{|c|}{ Act evaluation $^{\mathrm{b}}$} \\
\hline Moral items & 2.72 & 2.70 & 2.53 & 2.67 \\
\hline Conventional & 2.36 & 2.06 & 2.03 & 2.16 \\
\hline Personal & 1.87 & 1.54 & 1.49 & 1.64 \\
\hline Contextual & 2.29 & 2.04 & 1.86 & 2.08 \\
\hline Prudential & 2.36 & 2.18 & 2.07 & 2.21 \\
\hline
\end{tabular}

Table 2: Mean Judgments (in \%) of Authority Legitimacy and Personal Jurisdiction and Mean Ratings of Acts and Rules (by grade)

${ }^{a}$ On a scale from 1 (very unreasonable) to 5 (very reasonable).

${ }^{b}$ On a scale from 1 (not severe) to 3 (very severe).

Likewise, moral and prudential rules were rated more positively and moral and prudential violations were rated more negatively than all other rules and acts or rule violations (see Table 2 for means). Conventional rules were rated more positively and conventional violations were rated more negatively than contextually conventional and personal rules or rule violations, respectively. Rules concerning contextually conventional issues were rated more positively than rules concerning personal issues, 
and violations of contextually conventional rules were rated more negatively than personal violations.

\begin{tabular}{|l|l|l|l|}
\hline \multicolumn{5}{|c}{ Area } \\
\hline & Countryside & Big city & M \\
\hline Legitimacy & & & \\
\hline Moral items & 95.3 & 95.1 & 95.2 \\
\hline Conventional & 88.0 & 80.1 & 84.3 \\
\hline Personal & 46.9 & 31.3 & 39.5 \\
\hline Contextual & 80.0 & 58.7 & 70.0 \\
\hline Prudential & 90.4 & 83.0 & 86.9 \\
\hline Personal jurisdiction & & & \\
\hline Moral items & 39.2 & 45.6 & 42.2 \\
\hline Conventional & 41.4 & 57.7 & 49.1 \\
\hline Personal & 67.5 & 85.8 & 76.2 \\
\hline Contextual & 38.6 & 70.3 & 53.6 \\
\hline Prudential & 39.8 & 57.1 & 48.0 \\
\hline Rule evaluation ${ }^{\mathrm{a}}$ & & & \\
\hline Moral items & 4.33 & 4.20 & 4.27 \\
\hline Conventional & 3.99 & 3.80 & 3.91 \\
\hline Personal & 3.05 & 2.35 & 2.71 \\
\hline Contextual & 3.87 & 3.16 & 3.54 \\
\hline Prudential & 4.26 & 4.00 & 4.14 \\
\hline Act evaluation ${ }^{\mathrm{b}}$ & & & \\
\hline Moral items & 2.71 & 2.62 & 2.67 \\
\hline Conventional & 2.26 & 2.03 & 2.16 \\
\hline Personal & 1.78 & 1.47 & 1.64 \\
\hline Contextual & 2.25 & 1.88 & 2.08 \\
\hline Prudential & 2.25 & 2.16 & 2.21 \\
\hline & & & \\
\hline
\end{tabular}

Table 3: Mean Judgments (in \%) of Authority Legitimacy and Personal Jurisdiction and Mean Ratings of Acts and Rules (by area)

a On a scale from 1 (very unreasonable) to 5 (very reasonable).

${ }^{b}$ On a scale from 1 (not severe) to 3 (very severe).

The ANOVAs also revealed significant main effects for grades for judgments of legitimacy and personal jurisdiction and ratings of rules and act severity, $\mathrm{F}(2,287)=9.23$, $24.79,15.76,20.61, \mathrm{p}<.0001$, respectively. Seventh graders viewed all rules as more legitimately subject to teachers' authority than did older students, whereas older students viewed all acts as under personal jurisdiction more than did seventh graders (see Table 2 for means). Seventh graders also evaluated rules more positively than did ninth and 
eleventh graders, and acts more negatively than did older students. Finally, ninth graders rated acts more negatively than did eleventh graders.

There were significant main effects for area in legitimacy, personal jurisdiction, and ratings of rule and act severity, $F(1,287)=21.71,16.46,26.53,34.26, p<.0001$, respectively. Students came from countryside believed teachers had more authority over conventional, personal, contextually conventional, and prudential rules, $F(1,301)=$ $6.80,26.11,40.00,8.59, p<.05, .0001, .0001, .01$, respectively (see Table 3 for means), but there was no significant difference on moral rules, and the majority (over 95\%) of students confessed teachers' authority over moral issues. Conversely, students came from countryside endorse less personal jurisdiction on conventional, contextually conventional, personal, and prudential issues, $F(1,301)=12.63,23.73,57.09,12.80$, $p<.0001$, respectively. However, no significant difference was found between moral issues (see Table 3 for means). The ANOVAs also revealed significant difference across all domains concerning rule evaluation, $F(1,301)=4.26,5.28,47.72,51.39,9.34$, p < $.05, .05, .0001, .0001, .01$, respectively. Finally, students came from countryside rated act violations in moral, conventional, personal, and contextual conventional domains more severely than did students came from big cities, $F(1,301)=5.92,18.64,40.80,46.61 ; p$ $<.05, .0001, .0001, .0001$, respectively. But there was no significant difference between prudential violations (see Table 3 for means).

\subsection{Alternative authority sources}

As can be seen in Table 4, the majority of students regarded teachers and principals as having authority over moral and conventional issues, but most of them rejected their authority over personal issues. About half of the adolescents endorsed authority to law, parents, and themselves over moral issues. Also about half of them believed themselves had authority over conventional issues. The majority of students regarded themselves as the authority over personal issues. It's also interesting to notice that almost half (46\%) of the students endorsed authority to parents over personal issues. Teachers also had the most authority over contextual conventional and prudential issues (about 71\% each), while students themselves and parents were endorsed more authority in personal and prudential issues (about half) than other sources of authority except teachers.

\subsection{Ratings of school context}

Students reported that, on average, acts were governed by rules $(M=2.21)$, and that they only had a moderate amount of input in decision making $(M=2.39)$. Separate ANOVAs revealed significant main effects for domain in ratings of rule existence and opportunities for decision making, $F(4,1108)=115.81,60.90$, respectively; $p<.0001$. Students reported they had more moral and contextually conventional rules than other types of rules; and they had more conventional and prudential rules than personal rules (See Table 5 for means). 


\begin{tabular}{|l|l|l|l|l|l|}
\hline \multicolumn{7}{|c|}{ Contextual } \\
\hline & Moral & Conventional & Personal & Convention & Prudential \\
\hline Self & 47.0 & 49.6 & 73.7 & 54.2 & 49.7 \\
\hline Parents & 47.7 & 24.4 & 46.4 & 39.4 & 58.7 \\
\hline Teachers & 66.5 & 73.0 & 37.8 & 71.2 & 71.7 \\
\hline Headmaster & 57.2 & 59.2 & 26.3 & 47.0 & 48.9 \\
\hline Law & 53.3 & 10.5 & 7.6 & 11.8 & 50.8 \\
\hline
\end{tabular}

Table 4: Mean Endorsement (in \%) of Alternative Authority Sources

There were main effects for areas and grades in ratings of rules and input into decision making, $F(1,282)=48.50,13.47, p<.0001 ; F(1,282)=27.92,6.25, p<.0001, .01$, respectively. On average, students from countryside reported more rules in schools and more input in rule decision making, $M D=.22, .57$, respectively. Seventh graders reported more rules in schools and more input in rule decision making than did ninth and eleventh graders.

There was significant difference between boys and girls in ratings of rules, $F(1$, $282)=4.89, p<.05$. Boys reported more rules of all domains than did girls, $M D=.16$. But there was no significant gender difference in input into decision making.

\begin{tabular}{|c|c|c|c|c|}
\hline \multicolumn{5}{|c|}{ Grade } \\
\hline & 7 & 9 & 11 & M \\
\hline \multicolumn{5}{|c|}{ Existence of rules ${ }^{a}$} \\
\hline Moral items & 2.55 & 2.31 & 2.16 & 2.35 \\
\hline Conventional & 2.46 & 2.24 & 1.99 & 2.25 \\
\hline Personal & 1.95 & 1.86 & 1.61 & 1.83 \\
\hline Contextual & 2.43 & 2.45 & 2.11 & 2.35 \\
\hline Prudential & 2.51 & 2.13 & 2.04 & 2.24 \\
\hline \multicolumn{5}{|l|}{ Opportunities ${ }^{\mathrm{b}}$} \\
\hline Moral items & 2.93 & 2.38 & 2.44 & 2.58 \\
\hline Conventional & 2.91 & 2.38 & 2.54 & 2.60 \\
\hline Personal & 2.22 & 1.86 & 1.68 & 1.93 \\
\hline Contextual & 2.72 & 2.17 & 2.25 & 2.38 \\
\hline Prudential & 2.88 & 2.24 & 2.22 & 2.45 \\
\hline
\end{tabular}

Table 5: Ratings of Rule Existence and Opportunities for Decision Making

\footnotetext{
${ }^{a}$ On a scale from 1 (no firm rules) to 3 (firm rules).

${ }^{b}$ On a scale from 1 (no input) to 5 (a great deal of input).
}

\subsection{Self-reports of misconduct}

On average, students reported that they rarely misbehaved $(M=1.70)$. An ANOVA performed on self-reports of misconduct revealed a significant main effect for domain, $F$ $(4,1092)=403.18, p<.0001$. Adolescents reported more conventional misconducts than 
any other type of misconduct except personal behavior. They reported fewer prudential misconducts than any other types of misconducts and fewer moral violations than conventional and contextually conventional violations (See means in Table 6).

There were significant domain $\times$ grade, $F(4,1092)=9.25, p<.0001$, domain $\times$ area, $F$ $(4,1092)=13.29, p<.0001$ and domain $\times$ gender interaction, $F(4,1092)=9.82, p<.0001$. On average, eleventh graders reported more misconducts than did ninth graders, $\mathrm{MD}=1.04$; and ninth graders reported more misbehaviors than did seventh graders, MD=1.45. Students came from countryside generally reported more misconducts than did students from big cities. Finally, boys reported more misconducts of moral and prudential issues, while girls reported more misbehaviors of conventional, personal, contextually conventional issues.

\begin{tabular}{|l|l|l|l|l|}
\hline \multicolumn{5}{|c|}{ Grade } \\
\hline & 7 & 9 & 11 & $\mathrm{M}$ \\
\hline Teacher ratings & \multicolumn{5}{|c|}{} \\
\hline Moral items & $1.20(.37)$ & $1.94(.72)$ & $1.34(.38)$ & $1.46(.60)$ \\
\hline Conventional & $1.38(.39)$ & $1.98(.59)$ & $1.59(.63)$ & $1.62(.58)$ \\
\hline Personal & $2.26(.60)$ & $1.81(.40)$ & $3.09(.66)$ & $2.36(.74)$ \\
\hline Contextual & $1.28(.26)$ & $1.53(.41)$ & $1.87(.91)$ & $1.51(.60)$ \\
\hline Prudential & $1.16(.30)$ & $1.45(.31)$ & $1.74(.73)$ & $1.40(.51)$ \\
\hline Student ratings & \multicolumn{5}{|l}{} \\
\hline Moral items & $1.43(.42)$ & $1.51(.46)$ & $1.61(.49)$ & $1.51(.46)$ \\
\hline Conventional & $1.76(.58)$ & $2.13(.62)$ & $2.18(.76)$ & $2.02(.67)$ \\
\hline Personal & $2.43(.78)$ & $3.06(.73)$ & $3.55(.83)$ & $2.97(.88)$ \\
\hline Contextual & $1.44(.50)$ & $1.63(.54)$ & $2.07(.74)$ & $1.68(.63)$ \\
\hline Prudential & $1.32(.57)$ & $1.50(.63)$ & $1.46(.61)$ & $1.43(.58)$ \\
\hline
\end{tabular}

Table 6: Mean Teacher and Student Ratings Misconduct

${ }^{a}$ On a scale from 1 (never) to 5 (very frequently).

\subsection{Correlations between Student and Teacher Ratings of Conduct}

Mean teacher ratings for conduct in different domains also presented in Table 6. For all students, mean teacher' and students' ratings of students conventional, personal behavior were moderately but significantly related ( $\mathrm{rs}=.31,30$, ps<.001), whereas their ratings of moral, contextually conventional, and prudential behavior were weakly but significantly related (rs=.12, .19, .13, ps<.05).

Correlated t tests indicated that across domains, students consistently rated themselves as engaging in more misconduct than did their teachers.

\subsection{Multiple factor regressions on misconduct}

In the next set of analyses, the relative contributions of adolescents' ratings of rules (as assessed by act severity, rule evaluation, and legitimacy judgments), their evaluations of the school context (as assessed by ratings of rule existence and opportunities for decision making), 
background characteristics (gender, age, and parents' marital status, scored as married, intact families vs. all else), and orientations toward school (self-reports of academic performance and liking for school) on school-related misconduct were examined using multiple regression analyses. To alleviate some of the problem associated with the use of self-report data, and because teacher and self-report ratings were significantly correlated, composite teacher and student ratings of misconduct were created by obtaining mean teacher and student ratings of overall misconducts and of misconducts in each domain.

\begin{tabular}{|c|c|c|c|c|}
\hline \multicolumn{5}{|c|}{ independent/coefficient of R square F stanc } \\
\hline \multicolumn{5}{|c|}{ dependent factor determination } \\
\hline & change & \multicolumn{3}{|c|}{ Regression Coefficient } \\
\hline & $\left(R^{2}\right)$ & \multicolumn{3}{|c|}{$(\Delta R)$} \\
\hline \multicolumn{5}{|c|}{ Misbehavior (overall) $\mathrm{R}^{2}=\mathbf{0 . 4 1 2}$} \\
\hline age & 0.245 & 0.245 & 80.422 & 0.407 \\
\hline authority legitimacy & 0.399 & 0.155 & 81.216 & -0.370 \\
\hline like school & 0.412 & 0.012 & 57.393 & 0.117 \\
\hline \multicolumn{5}{|c|}{ Moral misbehavior $\mathrm{R}^{2}=0.169$} \\
\hline rule existence & 0.075 & 0.075 & 22.417 & -0.204 \\
\hline gender & 0.115 & 0.039 & 12.264 & 0.215 \\
\hline rule evaluation & 0.152 & 0.037 & 12.062 & -0.200 \\
\hline like school & 0.169 & 0.017 & 5.169 & 0.317 \\
\hline \multicolumn{5}{|c|}{ Conventional misbehavior $\mathrm{R}^{2}=0.238$} \\
\hline age & 0.095 & 6.095 & 29.759 & 0.265 \\
\hline authority legitimacy & 0.161 & 0.066 & 22.219 & -0.150 \\
\hline gender & 0.195 & 0.034 & 11.790 & 0.199 \\
\hline like school & 0.213 & 0.018 & 6.274 & 0.116 \\
\hline $\begin{array}{l}\text { decision } \\
\text { opportunity }\end{array}$ & 0.224 & 0.012 & 4.226 & 0.140 \\
\hline rule evaluation & 0.238 & 0.014 & 4.987 & -0.161 \\
\hline \multicolumn{5}{|c|}{ Personal misbehavior $\mathrm{R}^{2}=0.505$} \\
\hline authority legitimacy & 0.288 & 0.288 & 112.776 & -0.292 \\
\hline age & 0.409 & 0.121 & 57.146 & 0.398 \\
\hline area & 0.482 & 0.072 & 38.661 & -0.253 \\
\hline rule existence & 0.498 & 0.017 & 9.157 & -0.135 \\
\hline gender & 0.505 & 0.007 & 3.933 & -0.086 \\
\hline \multicolumn{5}{|c|}{ Contextually conventional $\mathrm{R}^{2}=0.314$} \\
\hline age & 0.207 & 0.207 & 75.666 & 0.387 \\
\hline authority legitimacy & 0.257 & 0. & 19.643 & -0.256 \\
\hline $\begin{array}{l}\text { decision } \\
\text { opportunity } \\
\end{array}$ & 0.284 & 0.026 & 10.527 & 0.174 \\
\hline rule existence & 0.299 & 0.016 & 6.474 & -0.175 \\
\hline area & 0.314 & 0.015 & 6.267 & 0.142 \\
\hline \multicolumn{5}{|c|}{ Prudential misbehavior $\mathrm{R}^{2}=0.254$} \\
\hline rule evaluation & 0.125 & 0.125 & 41.639 & -0.317 \\
\hline age & 0.192 & 0.067 & 23.995 & 0.291 \\
\hline gender & 0.254 & 0.062 & 24.019 & 0.252 \\
\hline
\end{tabular}


As presented in Table 7, teachers' and students' reports of overall misconducts were significantly predicted by student's age, their endorsement of authority legitimacy, and their attitudes towards school (whether they like it or not). Misconducts were reported to be on increase with age in all domains except moral issues. More misconducts also were reported among students who endorsed less authority legitimacy on teachers. Finally, the more they liked the school, the fewer rule violations students conducted. These three variables accounted for $41.2 \%$ of the variance in misconduct.

Moral rule violations were significantly predicted by students' ratings of rule existence, evaluations of rules, whether they like school, and gender (as noted previously, boys engaged in more moral violations than girls). Together these variables accounted for $16.9 \%$ of the variance in reported moral misconducts.

Teacher- and student-reported misconducts in conventional domain were significantly predicted by students' endorsement on teacher authority, opportunity in rule decision making, and evaluations of rules. The less or lower those factors were, the more rule violations in conventional domain. Meanwhile, when growing older, students reported more conventional rule violations; boys and those who felt less liking to school reported more transgressions in conventional domain. Totally, these six variables accounted for $23.8 \%$ of the variance in teacher- and student-rated conventional misconducts.

More teacher- and student-reported misconducts in personal domain were significantly predicted by authority endorsement (being less), ratings of rule existence (being lower), age (being older), and living areas (living in big cities). These variables together accounted for $50.5 \%$ of the variance in personal transgressions.

As in other domains, reported contextually conventional misbehaviors increased with age; when students had less endorsement on teachers' authority, lower ratings of rule existence and opportunity in decision making, they engaged in more transgressions in contextually conventional domain; students lived in big cities engaged in more contextually conventional misconducts than students from countryside. These variables totally accounted for $31.4 \%$ of the variance in student and teacher -reported misbehaviors in contextually conventional domain.

Prudential misconducts were significantly predicted by rule evaluation, age and gender. When students held a more negative attitude towards the reasonability of prudential rules, they were more likely to conduct misbehaviors; prudential misbehaviors also increased with students' age; female students reported more transgressions prudential domain than male students did. The three variables accounted for $25.4 \%$ of the total variance of misconducts in prudential issues. 


\section{Discussion}

\subsection{Evaluations of acts and rules}

As anticipated, adolescents' conceptions of school and teacher authority were differentiated according to conceptual domains. Most adolescents viewed moral, conventional, and prudential issues as legitimately regulated by teachers and school administrators (above 80\%), but less legitimacy was endorsed to contextually conventional issues (less than 70\%), and personal issues gained the least legitimacy of teacher authority (less than $40 \%$ ). Teachers had the highest authority to make rules on moral issues, followed by conventional and prudential issues; making rules was considered the most unreasonable and unacceptable in personal domain.

These results were consistant with former similar researches and may have important implications for moral and disciplinary education. For example, Killen et al. (1995) found that children and adolescents' acceptance or rejection to principles and rules made by adults in moral and conventional domain depended on their evaluation and judgment of these rules, demands or expectations. Even if they believed that the they were reasonable, children and adolescents would actively evaluate the way adults pass these rules to see if these methods were appropriate with domains. When the adult's interpretations were domain-appropriate, adolescents were more likely to accept these rules and interpretations; otherwise they were more possible to reject them. Therefore, it's suggested that teachers keep the concept of domains in mind when react to students' transgressions and violations. Specifically, when a teacher deals with a students' moral violation, he/she should clearly states that their behaviors may harm others, infringe the rights of others, or may result in unfair concequences. In this way, rules and regulations are more likely to be recognized by students, thereby to terminate their violations in then situations and reduce violatons in the future; when a student commits a conventional violation, the teacher should focus on the importance of this conventional rule in maintaining class order and school functioning, rather than simply ordering or forbidding them; for a prudential violation, the teacher should focus on the possible harm and serious consequences to themselves; as for violations in contextually conventional and personal domains, teachers need to be particularly cautious when intervening because students are less receptive to teachers' authority in these two domains. What's more, if the teacher's approach is inconsistent with students' conceptual domains, they are more possible to transgress or resist.

There were main effects of grades in the legitimacy of teachers' authority, personal jurisdiction, rule evaluation and act assessment. Adolescents' personal jurisdiction increased with age in all domains, especially in prudential and contextually conventional domain. This is consistent with previous studies. Smetana (1988) found that the legitimacy of parental authority in the pre-youth (grades 5 and 6) and puberty (grades 7-12) decreased, while individual autonomy increased, especially in the personal and overlapping domains. Coupled 
with the dramatic changes in their physical aspects, adolescents' desire and ability on their own body also enhance, and prefer to engage in some risky activities. Therefore, their personal jurisdiction in prudential domain increases dramatically. But parents often prefer to control those activities, which in turn leads to parent-child conflicts. So teachers should be aware of the adolescents' demand for autonomy and, within as far as possible, give them the right to make their own decisions, and avoid all-round control. For prudential events, teachers should make students understand the impulse of their own physical changes, and use real examples to explain the possible consequences of risky activities, rather than blindly force or control them; otherwise it will only lead to strong resistance from adolescents. In addition to the moral domain, adolescents from rural areas and cities had significant differences in the legitimacy of teacher authority, personal jurisdiction, rule evaluation and act assessment. In general, rural adolescents were more likely to recognize teachers' autonomy in conventional, contextually conventional, prudential and personal domains than urban adolescents. This supports some former researches. For example, Geogras et al. (1989) found that even in the same culture, urban subjects were more inclined to individualism, and traditional rural subjects were more inclined to collectivism. In other words, urban adolescents were more autonomous, and could insist on their own inner ideas to action. This may be related to urban students' relatively more extensive knowledge and experience, which is related to the family environment. In general, urban parents have higher culture level, and may adopt more democratic ways in child-raising. That's to say, urban families may pay more attention to cultivate the child's sense of autonomy and critical thinking, so urban adolescents' obedience to authority is more rational or less blind. While rural adolescents are more inclined to obey all the instructions from authorities, including parents and teachers, and tend to suppress their own personal feelings and thoughts. This suggests that students from different cultural backgrounds may have different cognitions and understandings to teacher authority. Teachers should be aware of those diffences. On the other hand, it also shows that students' low acceptance to teacher authority is not necessarily a bad thing, because it may suggest that their critical thinking is developing.

\subsection{The predicting factors of students' rule violation at school}

While students' self-reported rule violations may be fewer than actual ones, it is interesting to note that in all domains, teachers reported fewer rule violations than students did. There are two possible reasons: First, because some disciplinary behaviors, such as smoking, drinking, etc. mostly occurred when teachers were absent, so they had no idea about this; another possible reason is that teachers were more inclined to provide answers according with social expectations. Teachers may regard students' behaviors as indications of their own educational performance; or because teachers often communicate with students, so lead to the so-called halo effect. However, there was a significant correlation between the teacher's assessment of rule violations and the 
student's self-reported disciplinary behaviors. So it's reasonable to take the average of the two as a measure of student misconducts, and to reduce the shortcoming of self-report data to some extent. In the future study, it will be more scientific and comprehensive if some relatively objective observation data can be added.

In general, age was a powerful factor in predicting students' rule violations, which explained $24.5 \%$ of violations to school discipline. Except moral domain, rule violations in other domains increased with age, especially in contextually conventional domain $\left(R^{2}=0.207\right)$, personal domain $\left(R^{2}=0.121\right)$ and the conventional domain $\left(R^{2}=0.095\right)$. This shows that adolescents' concept was in a period of rapid development, especially in personal and conventional domain. Therefore, teachers should take into account the characteristics of adolescent's psychological development when implementing school discipline, and fully consider their developmental requirements for personal jurisdiction. This in in line with the thoughts of developmental disciple. Watson(2008) proposed a developmental perspective in education-a sense of what the developmental tasks are for children of different ages and the appropriate role of adults in assisting the child's development. That's to say, children should be seen as being in the process of development and naturally want to build their understanding of their world, but they are still developing the competencies needed to succeed. From this perspective, student misbehaviors are mistakes, and mistakes are opportunities for learning. Meanwhile teachers can enhance children's moral understanding by involving them in developing class rules and norms and in the responsibility for seeing that the rules and norms function well. This is also a good way to satisfy their requirements for jurisdiction.

The legitimacy of teacher authority can also effectively predict adolescents' rule violations at school, which can explain $15.5 \%$ of the total transgressions. The legitimacy of teacher authority was an effective predictor of violations in conventional, personal and contextually conventional domain, especially in the personal domain, which can explain $28.8 \%$ of the transgressions; but it cannot effectively predict violations in moral and prudential domain. This is consistent with the characteristics of domains advocated by domain researchers, in which moral and prudential actions are judged by their inherent consequences (moral transgressions are judged by the harm to others; while prudential transgressions are determined by the harm to oneself). So the assessment of the legitimacy of the teacher's authority did not fundamentally affect the student's judgment of these acts, and naturally cannot effectively predict violations in these two domains. In contrast, the criteria for judging transgressions in conventional, personal, and contextually conventional domain are mainly external, rather than the consequences of the act itself. Therefore, whether students recognize the legitimacy of teacher authority can largely affect students' behaviors. When students highly accept the legitimacy of teacher authority, their violations in these domains will be fewer; on the contrary, when students have a lower recognition of the legitimacy of teacher authority, they may conduct more 
transgressions. Therefore, the legitimacy of teacher authority in these domains need to be recognized by students before it can effectively influence the behavior of students. How to obtain teacher authority on those issues is the thing schools and teachers should focus on.

Whether like school or not was also an effective predictor of adolescent delinquent behaviors, especially in moral and conventional domain. The more students liked school, the less disciplinary behavior occurred, and vice versa. This is consistent with previous studies. Such as Smetana \& Bitz (1996) found that the more positive the evaluation of school life, and the higher degree of participation in school activities, the less discipline violations occurred among students. Arsenio and others (1999) believed that emotion played an important role in moral development: when children and adolescents were in a warm and fair environment, they would experience the world as a beautiful place, thus promoting their moral development. When children help others, moral behaviors will bring them a positive and happy mood, so as to believe more that the world is warm and beautiful. On the contrary, if children and adolescents suffer from deception and peer exclusion for a long time, they will deviate from the normal moral and reciprocal behavior patterns and show aggression against others. This is also the reason why domain theory researchers attach great importance to emotions in moral development. Dewey (1975) also argued that the mode of social life and the nature of the school community were far more important factors in students' moral growth than direct moral instruction. So teachers must pay attention to students' emotional needs when carrying out school discipline and try hard to build a positive relationship with students. Only when students form positive emotions towards the school, they are more likely to comply with the rules and regulations of the schools.

In addition, gender also was a valid factor in predicting disciplinary behaviors in moral, conventional, personal and prudential domain. Boys were more likely to violate discipline in moral, conventional and prudential domain, which may be related to the patterns of behavior that have been analyzed above. Female students had more violations in personal domain than male students. This may relate to female students' enthusiasm in personal issues, such as hairstyles, jewelry wearing, etc.

\section{References}

Smetana J. G. \& Asquith P. 1994. 'Adolescents' and Parents' Conceptions of Parental Authority and Personal Autonomy." Child Development 65(4):1147-62.

Smetana J. G. \& Bitz B. 1996. „Adolescents' Conceptions of Teachers' Authority and Their Relations to Rule Violations in School." Child Development 67(3):1153-72. 
Smetana J. G. 1998. „Concept of Self and Social Convention: Adolescents' and Parents' Reasoning about Hypothetical and Actual Conflicts," in M. Gunnar \& W. A. Collins" (Eds.), Minnesota Symposium on Child Psychology 21:79-122.

Tisak M. S. \& Turiel E. 1984. “Children’s Conceptions of Moral and Prudential Rules." Child Development 55(3):1030-9.

Turiel E. 1983. The Development of Social Knowledge: Morality and Convention. Melbourne: Cambridge University Press.

Watson M. 2008. "Developmental Discipline and Moral Rducation," in L. P. Nucci \& D. Narvaez (Eds.), Handbook of Moral and Character Education. New York: Routledge (175-203).

Yu Zh. 2005. „Teacher Authority in the Eyes of Rights and Power.” Journal of Jiangsu University (Higher Education Study Edition) 2:57-60.

Zhang L. \& Li R. 2003. "On the Modern Transition of Teachers' Authority." Educational Research 11:69-74.

\section{Acknowledgments}

This article is granted by School of English and Education, Guangdong University of Foreign Studies. 


\title{
Jianjin Liu \\ (Guangzhou)
}

\section{Chinese Adolescents' Conceptions of Teacher's Authority and Their Relations to Rule Violations in School}

\begin{abstract}
Based on the Social Cognitive Domain Theory, the paper explored the adolescents' conceptions of teacher authority in different domains and their relations to rule violations in school. The main results are: 1) Adolescents viewed moral, conventional, and prudential issues as legitimately subject to teachers' authority and personal issues as under personal jurisdiction, but they were equivocal about contextually conventional issues. 2) Seventh graders judged all acts as more legitimately subject to teachers' authority, all rule violations as more negative than did older students. 3) Compared with adolescents from big cities, adolescents from rural area viewed moral, conventional, contextually conventional, and personal issues as more legitimately subject to teacher authority, and endorsed less personal jurisdiction over those issues; but there were no significant differences in moral domain. 4) Male subjects reported more violations in conventional and prudential domain. 5) Adolescents' older age, less endorsement of legitimacy of teacher authority, and greater dislike for school predicted more teacher- and self-reported misconducts. Implications for moral education from these results were also discussed.
\end{abstract}

Keywords: Adolescents; Social Cognitive Domain Theory; conceptions of teacher authority; rule violations in school.

Ethics in Progress (ISSN 2084-9257). Vol. 9 (2018). No. 1, Art. \#5, pp. 99-117.

Creative Commons BY-SA 3.0

Doi: 10.14746/eip.2018.1.5 